\title{
THE ANALYSIS OF PSYCHOPHYSIOLOGICAL CONDITIONS OF STRESS DYMAMICS IN CANDIDATES TO THE POSITION OF A PROFESSIONAL DIVER WITH CONSIDERATION OF THE PSYCHOLOGICAL ASPECTS OF DIVING
}

Małgorzata Remlein ${ }^{1)}$, Jacek Buczyński ${ }^{2}$, , Romuald Olszański ${ }^{1)}$, Andrzej Buczyński ${ }^{4)}$, Zdzisław Kobos ${ }^{5)}$, Dariusz Juszczak ${ }^{5}$

\footnotetext{
${ }^{1)}$ Maritime and Hyperbaric Medicine Department, Military Institute of Medicine, Gdynia, Poland

${ }^{2)}$ University of Health Education and Social Science, Łódź, Poland

${ }^{3)}$ Medical University of Lódź, Poland

4) The Cardinal Stefan Wyszyński University, Warsaw, Poland

5) 7 Naval Hospital, Gdańsk, Poland
}

\section{ABSTRACT}

The article presents a characterisation of stress situations and psychological reactions during diving. It describes the fundamental personality dimensions and temperament features, and discusses the results of research into the methods of coping with stress as well as the levels of anxiety in candidates to the position of a professional driver.

Key words: physiological stress, psychological stress, panic, anxiety, diving stress, coping, temperament, personality.

\section{ARTICLE INFO}

PolHypRes 2015 Vol. 50 Issue 1 pp. 7 - 24

ISSN: 1734-7009 elSSN: 2084-0535

DOI: $10.1515 / \mathrm{phr}-2015-0001$

Pages: 18, figures: 22, tables: 0

page www of the periodical: www.phr.net.pl

Publisher

Polish Hyperbaric Medicine and Technology Society
Original article

Delivery date: 09.10.2014r.

Date of approval for print: $15.12 .2014 \mathrm{r}$ 


\section{INTRODUCTION}

In recent years diving has become a sporting activity available to millions of people around the world. However, to many of them the possessed skills, the physical and psychological preparation for this sport, are insufficient.

During professional courses a lot of attention is paid to knowledge of the diving equipment, illnesses connected with diving or diving safety issues. In amateur diving courses the said issues are merely touched up on or not discussed at all. A still neglected area involves the psychological aspects of diving. Water is not the natural environment of man, and the contact with it is a source of stress in many people.

Stress accompanying diving is a "silent perpetrator" in the majority of diving accidents. Understanding of the psychological aspects of diving, emotional reactions and cognitive processes connected with diving is of great significance. It is estimated that there are approximately 7 million people around the world practising recreational diving.

Besides this form, many people perform dives for scientific, commercial, filming, duty-related (e.g. military or investigative) and rescue purposes. The greatest challenge faced by professional diving today involves activities related to the search and extraction of oil from the sea bottom. Occupational diseases among this group constitute a large economic and social issue as they cause interruptions at work or even resignation from work by highly qualified and experienced staff.

Stress is defined in psychology as a dynamic adaptive relationship between the possibilities of an individual, and the requirements of a situation (stressor; aversive stimulus), characterised by a lack of balance. Undertaking remedial activities is an attempt to restore such a balance. In medical terminology, stress constitutes a disruption of homeostasis caused by a physical or psychological factor.

The factors inducing stress may be mental, physical, physiological or anatomic. For the purposes of diving terminology, stress may be defined as an unpleasant interaction between the diver and certain physical or emotional stimuli. Divers may experience two types of stress: physiological (sea sickness, hypothermia, fatigue, etc.) and psychological (anxiety, fear, embarrassment, panic, etc.).

The stress syndrome in diving may be recognised and well defined only on the basis of proper assessment of the complex correlations occurring between humans, their activity, and the environment in which it is conducted.

Stress is usually sudden and unexpected and surfaces when a person sees or experiences a threat to his/her life. The threat may be real, i.e. connected with the diving environment, the diving equipment or one's own well-being or ailments [1].

The majority of injuries in divers result from improper behaviour under stressful diving conditions, mainly due to panic occurring along with an increased anxiety level.

Divers with an elevated anxiety level and an unskilful manner of coping with stress are susceptible to a higher risk of developing a panic reaction as compared with those who possess more and better adjusted mechanisms of managing stress [2].

What has a great impact on the probability of occurrence of panic in a diver is his personality. In identical stress-inducing situations each diver will react differently.

Divers with high inclinations towards neuroticism will be the fastest to react with panic [3], the occurrence of which may be evoked by numerous factors. The initiation of panic is linked to the moment in which one loses selfconfidence or sense of security.

Next, once the diver loses control over the situation, the result is the so-called "vicious circle" of reactions and behaviours leading to further loss of confidence. Very quickly irrational behaviour overrides the rational one and the diver reaches the state where regaining self control becomes almost impossible.

When diver's panic we will often observe: quick and uncoordinated movements of the limbs and the body and irrational behaviour [3].

\section{MATERIAL AND METHODS}

The study supervised by Jacek Buczyński, Ph.D., entitled "The psychophysiological analysis of the dynamics of stress conditions of diver and combat diver profession candidates" examined 128 participants in the Naval diver training course - all of whom were serving compulsory military services.

The first stage of the psychological tests was conducted two weeks after the course commencement. Consecutive examinations were performed two months into the training, whereas the third phase was carried out immediately prior to the course termination. The thus programmed research scheme was to capture the dynamics of the psychological changes occurring in trainee divers. The subjects were aged between 19-25 years. Their education was: vocational, technical and general. [4].

All of the research stages were participated by the same seamen, however their number reduced throughout the duration of the course. Due to health reasons (both somatic and psychical) 29 people were required to resign from further participation in the course.

The assessment of candidates for professional diver training was performed with regard to the following characteristics: anxiety as a state and as a trait with the consideration of low and high self-assessment, neuroticisim, extraversion, openness to experiences, agreeableness, conscientiousness, styles of coping in stressful situations oriented on: tasks, emotions, avoidance, engagement in supplementary activities and seeking social contact, as well as traits of temperament; briskness, perseveration, sensory sensitivity, emotional reactivity, endurance and activeness.

Psychological tests were performed with the use of the following properly selected series of tests.

The first cycle of the study consisted of the following tests:

1. Formal Behaviour Characterisation - Temperament Questionnaire (FCZ-KT).

2. Personality Inventory NEO-FFI according to Costa and McCrae.

3. Matrix A, B, C, D and E Test, standard version according to Raven.

4. I-E Scale at work according to Rotter.

5. Questionnaire of Coping in Stressful Situations CISS.

6. Self-Assessment Questionnaire (STAI x-1) and (STAI x-2) according to Spielberger.

7.Stress Self-Assessment.

8. Personality Survey designed by the author. 
following tests:

The second cycle of the studies included the

1. Self-Assessment Questionnaire (STAI $x-1$ ).

2. Self-Assessment Questionnaire (STAI x-2).

3. I-E Scale at work.

4. Stress Self-Assessment.

The third cycle of the study contained all tests and questionnaires constituting the basis for the psychological tests applied in the first cycle [4].

\section{RESULTS}

Stress Self-Assessment (SPS) constituted the primary test used in the work. In the three stages of the study all of the tested candidates performed this test for the purpose of capturing the dynamics of stress in a given population in comparison with other psychological tests [4].

On the basis of the presented data we may conclude that the highest stress level among the subjects occurred at the beginning of the course $x=60.6+12.8$. In the light of the obtained results a statistically significant difference $(p<0.001)$ was observed with regard to the level of stress experienced by subjects in between the three phases of tests, i.e. at the beginning of training $(x=60.6)$, half way through $(x=56.7)$ and at the end of it $(x=53.6)$.

Fig. 1 presents graphic results of those studies.

\begin{tabular}{llll}
\hline Specification & Test 1 (SPS 1) & Test 2 (SPS 2) & Test 3 (SPS 3) \\
\hline Number of participants & 128 & 106 & 102 \\
\hline Min - Max & $42.0-103.0$ & $42.0-76.0$ & $39.0-93.0$ \\
\hline $\begin{array}{lll}\text { Median } \\
\text { Arithmetic Mean }\end{array}$ & 59.0 & 56.0 \\
\hline $\begin{array}{l}\text { Standard deviation } \\
\text { (SD) }\end{array}$ & 12.8 & 56.0 \\
\hline
\end{tabular}

Fig. 1. Self - Assessment of stress. Three-stageanalysis [4].

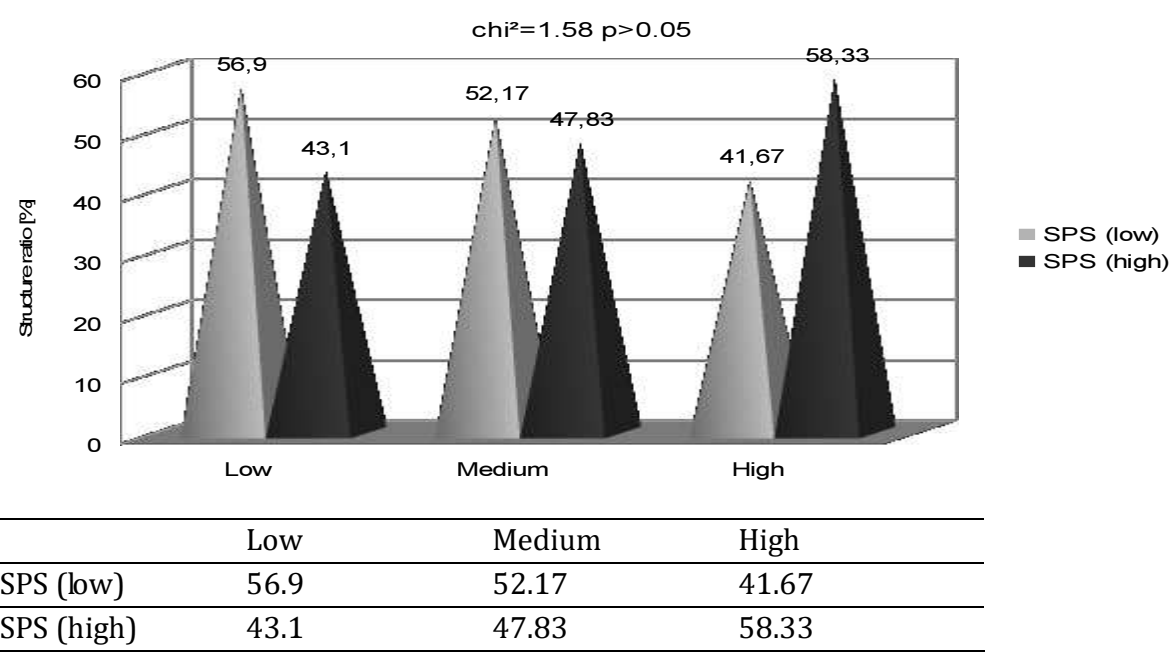

Fig. 2. Stress level percentage distribution based on Self-Assessment Test. Results involving three quantiles of Neuroticism dimension intensity. (Personality dimension of NEO-FFI Model) [4] 


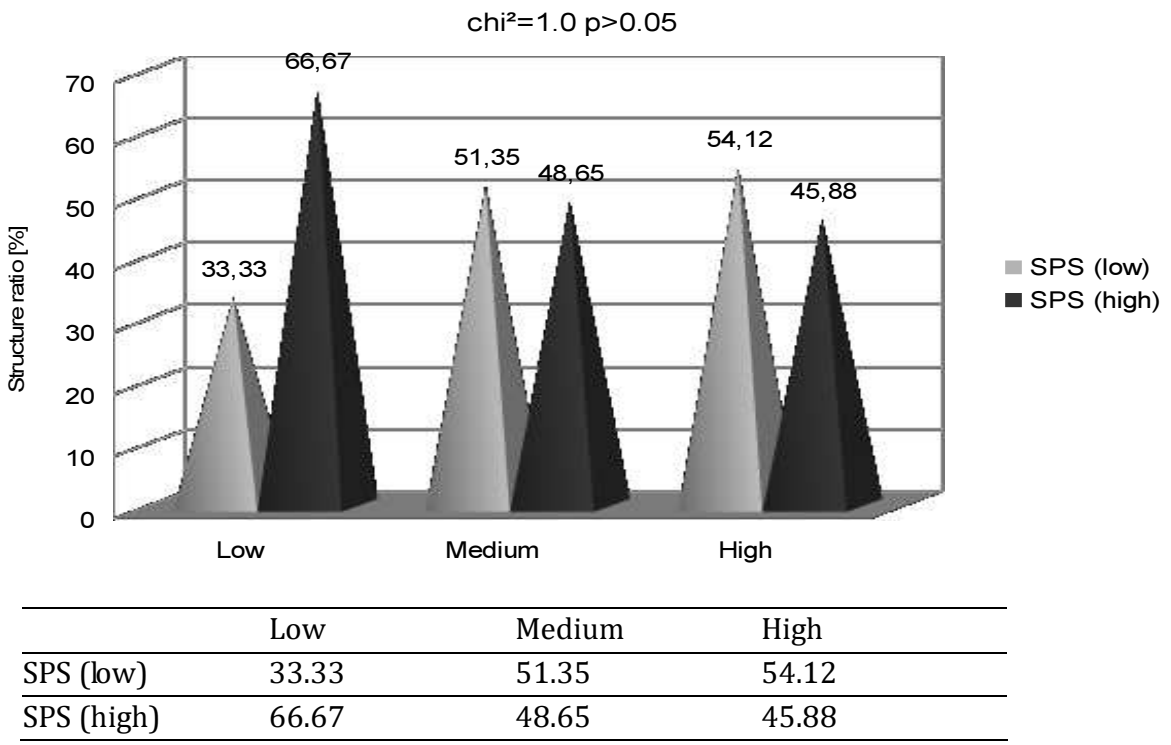

Fig. 3. Stress level percentage distribution based on Self-Assessment Test. Results involving three quantiles of Extraversion dimension intensity. (Personality dimension of NEO-FFI Model) [4].

\begin{tabular}{lllllll}
\hline \multirow{2}{*}{ SPS } & \multicolumn{5}{l}{$\begin{array}{l}\text { PERSONALITY DIMENSIONS } \\
\text { (NEO - FFI Model) }\end{array}$} \\
\cline { 3 - 7 } & & N & E & 0 & A & C \\
\hline \multirow{2}{*}{ Low } & R Spearman's rank correlation coefficient & 0,11 & 0,03 & 0,01 & $-0,17$ & $-0,29$ \\
\cline { 2 - 7 } & Statistical significance & $P>0,05$ & $P>0,05$ & $P>0,05$ & $P>0,05$ & $P<0,05$ \\
\hline \multirow{2}{*}{ High } & R Spearman's rank correlation coefficient & 0,22 & $-0,11$ & $-0,15$ & $-0,12$ & $-0,24$ \\
\cline { 2 - 7 } & Statistical significance & $P<0,08$ & $P>0,05$ & $P>0,05$ & $P>0,05$ & $P<0,07$ \\
\hline
\end{tabular}

Fig 4. R Spearman's rank coefficients of correlation between personality dimension intensity (NEO-FFI Model) and estimated level of stress (Self-Assessment test) (initial study I) [4]

During the analysis of the results presented in the table, it was concluded that the most diagnostically useful personality dimensions (conscientiousness and neuroticism) indicated a relevant significance in the evaluation of the stress level experienced by subjects in the course of the performed diving tasks.

The higher the level of conscientiousness, the lower the level of stress, whereas higher levels of neuroticism meant higher levels of stress. Any kinds of traits of irregular personality, and particularly a high level of neuroticism, had a negative effect on training results [4]. More detailed data are shown in fig. 4. 


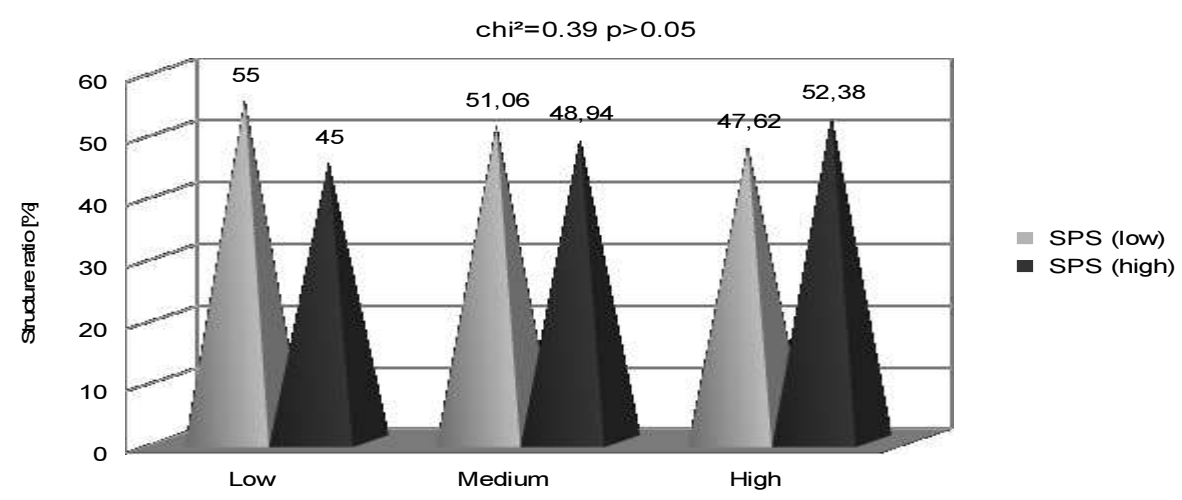

\begin{tabular}{llll}
\hline & Low & Medium & High \\
\hline SPS (low) & 55 & 51.06 & 47.62 \\
\hline SPS (high) & 45 & 48.94 & 52.38
\end{tabular}

Fig. 5. Stress level percentage distribution based on Self-Assessment Test. Results involving three quantiles of Openness dimension intensity. (Personality dimension of NEO-FFI Model) [4]

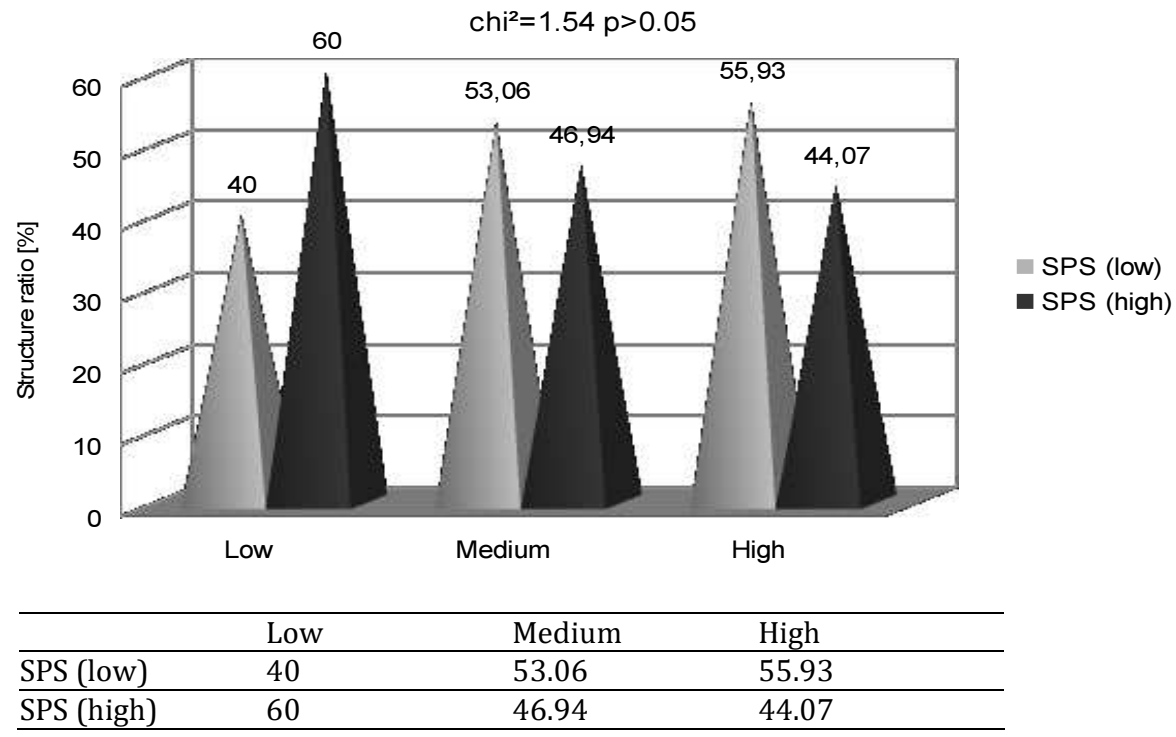

Fig. 6. Stress level percentage distribution based on Self-Assessment Test. Results involving three quantiles of Agreeableness dimension intensity. (Personality dimension of NEO-FFI Model) [4]. 


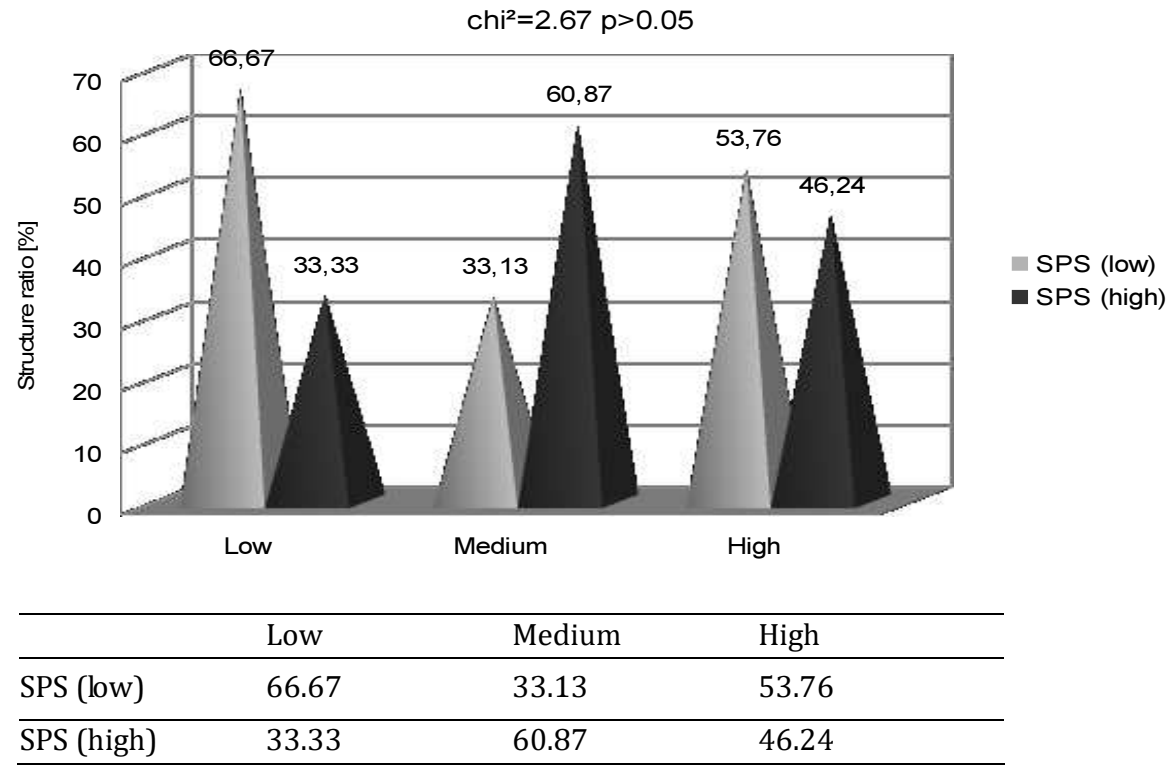

Fig. 7. Stress level percentage distribution based on Self-Assessment Test. Results involving three quantiles of Conscientiousness dimension intensity. (Personality dimension of NEO-FFI Model) [4].

It was concluded that the most diagnostically useful variables in the test were the personality variables, and in particular - conscientiousness.

Moreover, a tendency towards neuroticism was noted among the subjects. Graphic interpretation of the remaining personality dimensions is illustrated in fig. 2, 3, $5,6,7$.

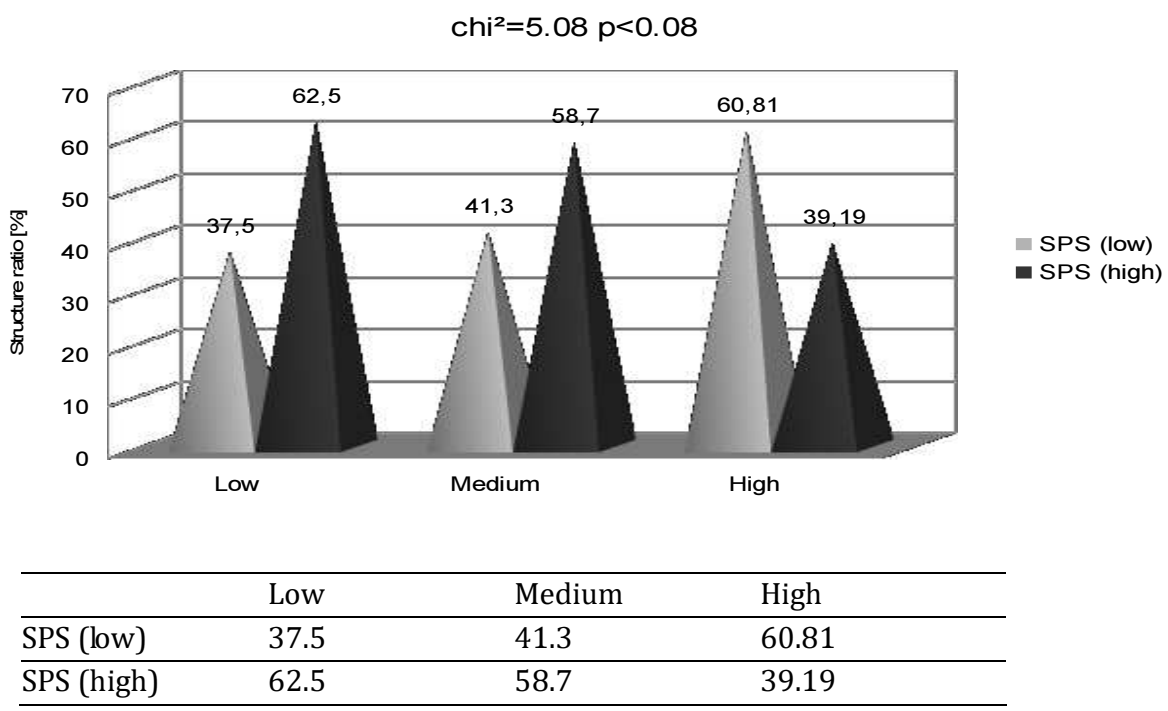

Fig. 8 Stress level percentage distribution based on Self-Assessment Test. Results involving three quantiles of Briskness dimension intensity. (Temperament dimension of FCZ-KT test) [4]. 
Briskness as a temperament dimension has a significant meaning in the evaluation of the stress level: the higher its level, the lower the level of stress. Positive correlation is also noted in relation to activeness - a higher level of activeness has an effect on higher levels of experienced stress.
A high level of emotional reactivity and perseveration led to an increased susceptibility to experiencing stress in the tested persons [4].

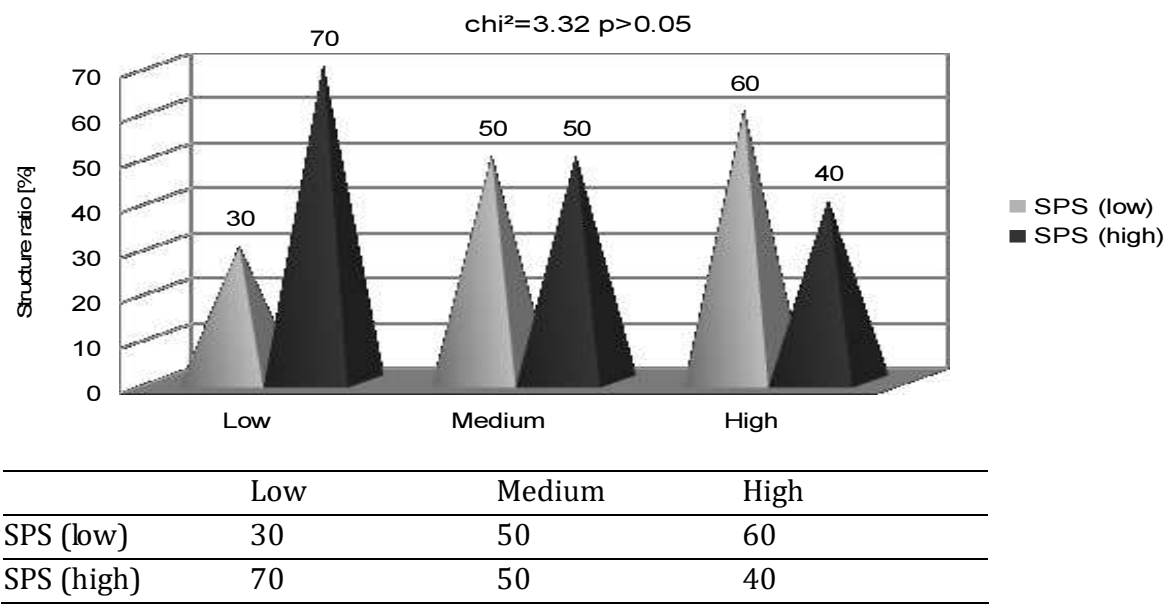

Fig. 9. Stress level percentage distribution based on Self-Assessment Test. Results involving three quantiles of Endurance dimension intensity. (Temperament dimension of FCZ-KT test) [4].

With regard to the self-assessment of the experienced stress, at a high level, of the six temperament dimensions, it appears that the significant ones include briskness, activeness, emotional reactivity and perseveration.

Subjects with low briskness levels expressed a low level of experienced stress. On the other hand, persons with a high level of endurance, sensory sensitivity, perseveration and emotional reactivity, indicated significance with regard to a high level of experienced stress (fig. 8, 9, 10, 11, 12, 13).

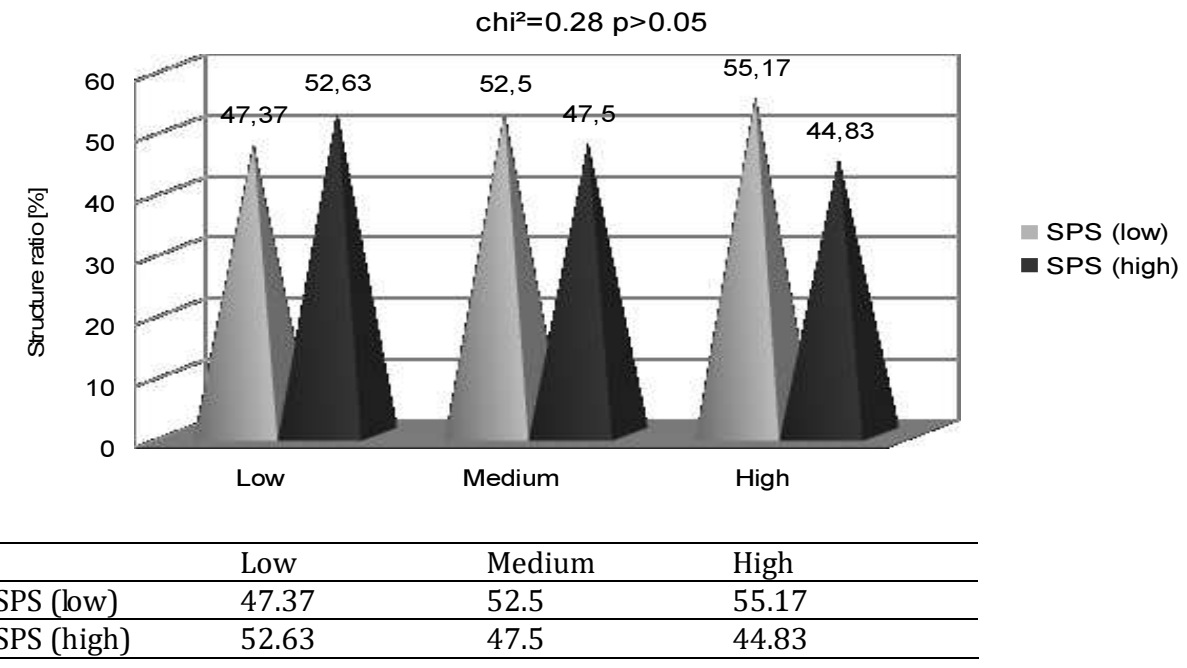

Fig. 10. Stress level percentage distribution based on Self-Assessment Test. Results involving three quantiles of Sensory Sensitivity dimension intensity. (Temperament dimension of FCZ-KT test) [4]. 


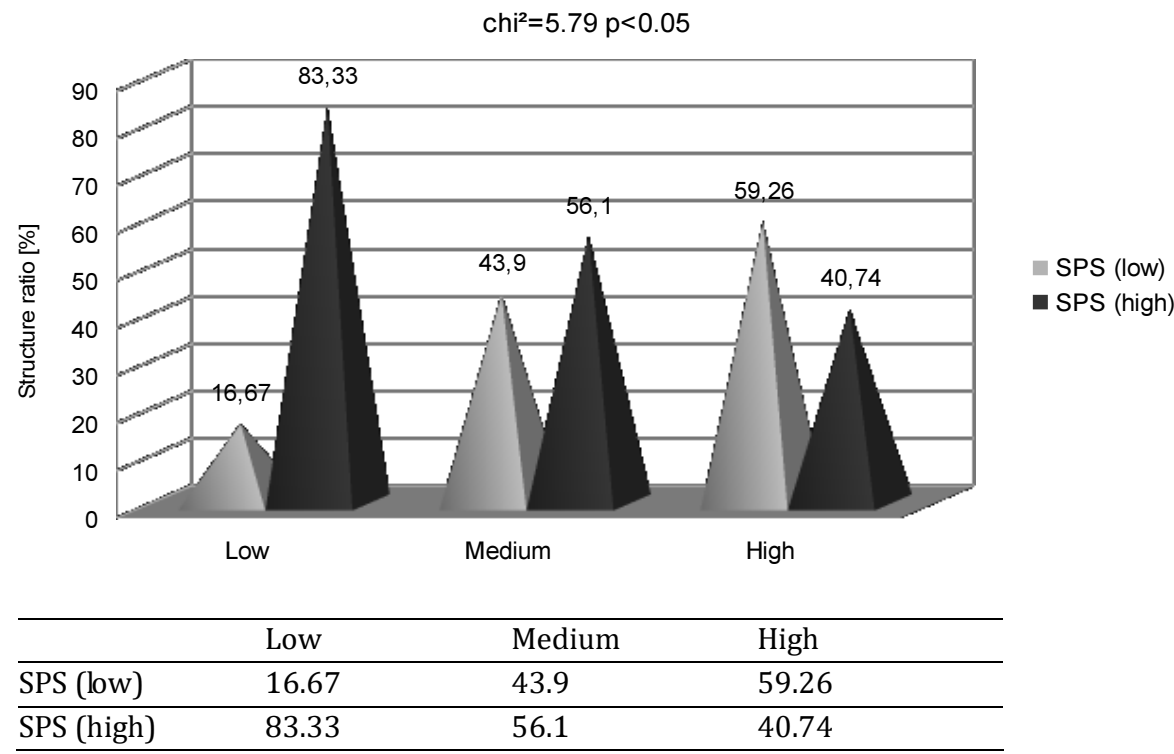

Fig. 11. Stress level percentage distribution based on Self-Assessment Test. Results involving three quantiles of Activity dimension intensity. (Temperament dimension of FCZ-KT test) [4]

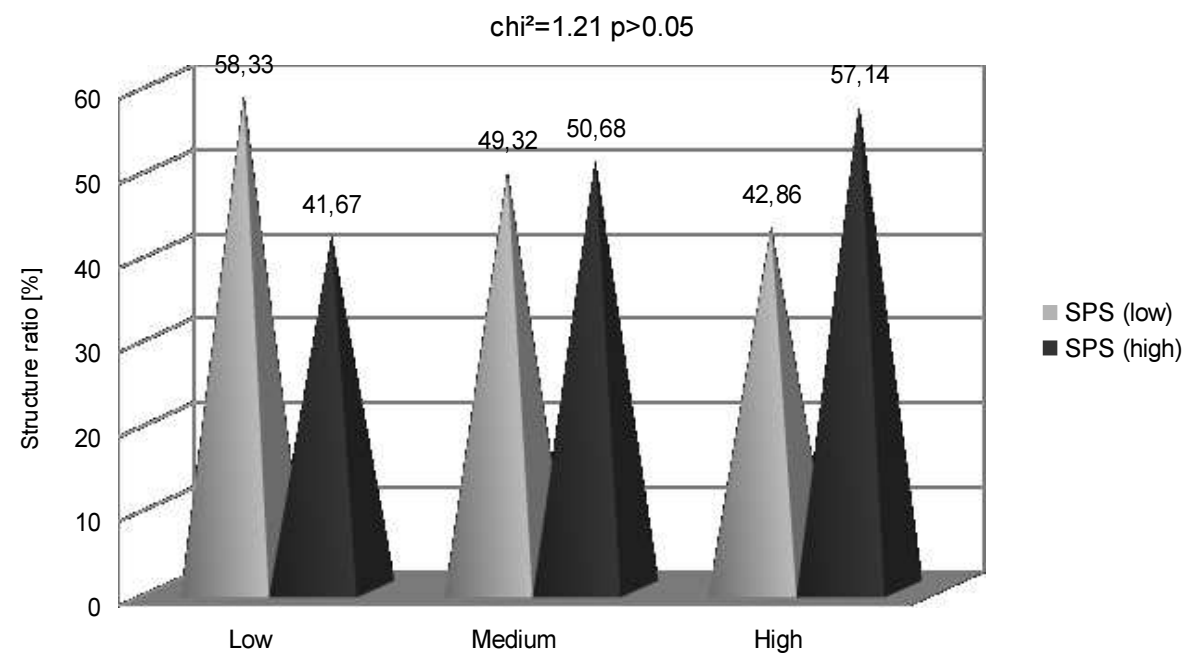

\begin{tabular}{llll}
\hline & Low & Medium & High \\
\hline SPS (low) & 58.33 & 49.32 & 42.86 \\
\hline SPS (high) & 41.67 & 50.68 & 57.14 \\
\hline
\end{tabular}

Fig. 12. Stress level percentage distribution based on Self-Assessment Test. Results involving three quantiles of Perseveration dimension intensity. (Temperament dimension of FCZ-KT test) [4] 


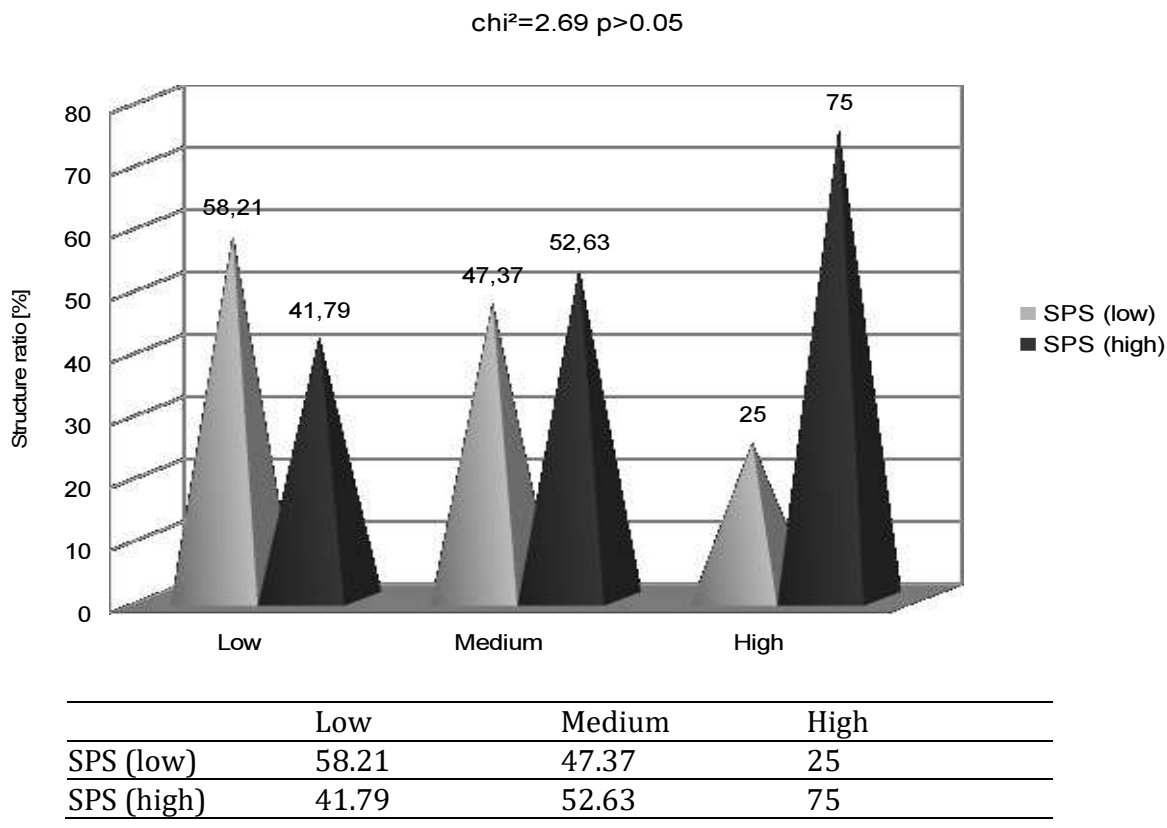

Fig. 13. Stress level percentage distribution based on Self-Assessment Test. Results involving three quantiles of Emotional Reactivity dimension intensity. (Temperament dimension of FCZ-KT test) [4].

The ways of coping with stress showed a statistically significant correlation with the selfassessment of the stress level: subjects preferring the styles connected with a high level of concentration on emotions or distracting attention from the existing problem were characterised by a high level assessment of the experienced stress [4].

The results are illustrated by Fig. 14 .

\section{STRESS COPING STRATEGIES}

SPS

TaskOriented EmotionalOriented

Avoidance Coping
Distraction SocialDiversion

0,14

0,11

R Spearman's rank correlation $\quad-0,17$

0,24

0,17

$\mathrm{P}>0,05$

$\mathrm{P}>0,05$

$\mathrm{P}>0,05$

Level of statisticalsignificance

$\mathrm{P}>0,05$

$\mathrm{P}<0,05$

0,07

0,20

$-0,11$

$-0,17$

0,44

$\mathrm{P}<0,05$

$\mathrm{P}>0,05$

$\mathrm{P}>0,05$

$\mathrm{P}>0,05$

Fig. 14. R Spearman's rank coefficients of correlation between stress coping strategies and estimated level of stress (Self-Assessment test) [4]. 


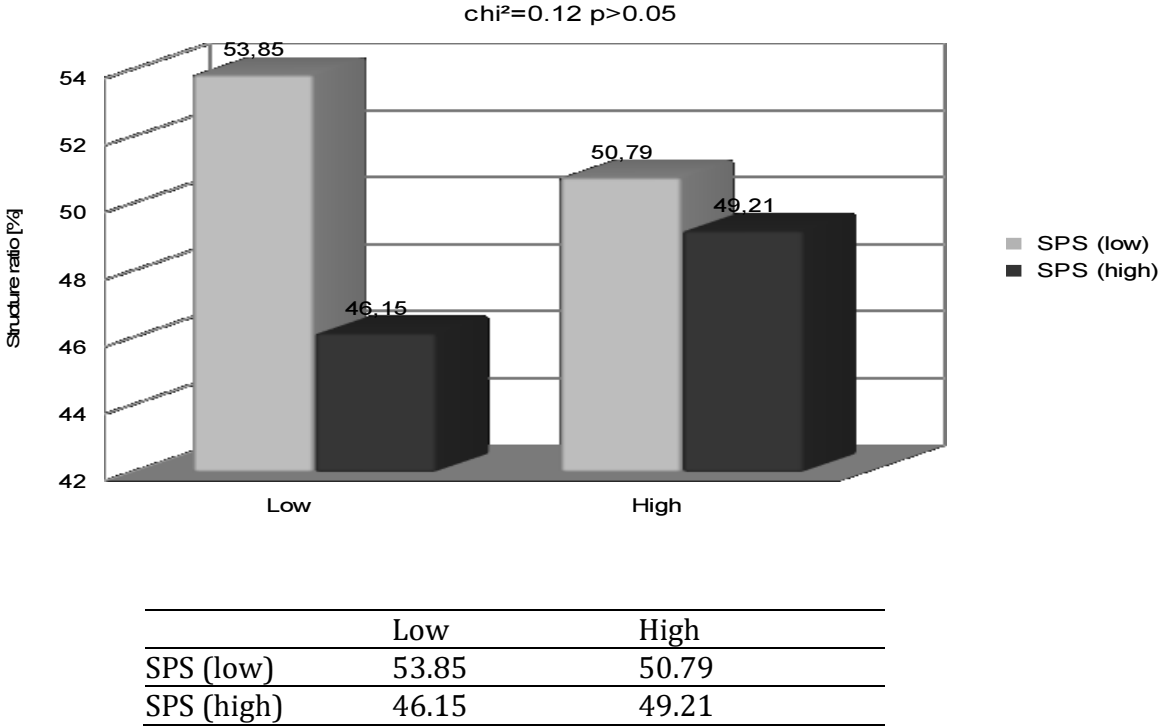

Fig. 15. Stress level percentage distribution based on Self-Assessment Test. Results involving subjects classified in terms of Task Oriented Stress Coping Strategy [4]

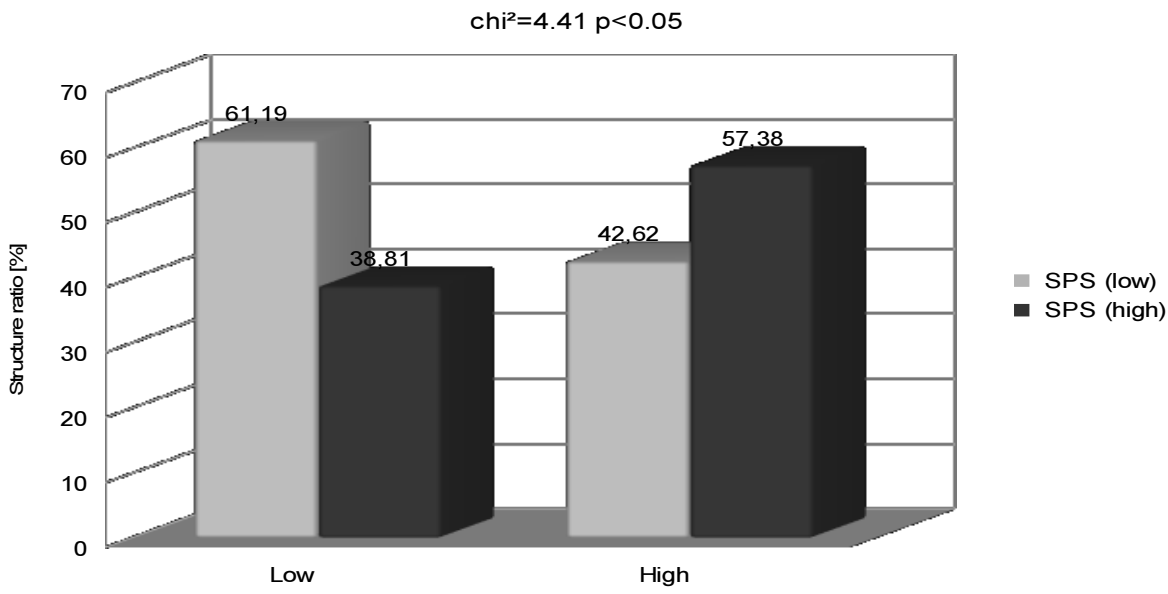

\begin{tabular}{lll}
\hline & Low & High \\
\hline SPS (low) & 61.19 & 42.62 \\
\hline SPS (high) & 38.81 & 57.38 \\
\hline
\end{tabular}

Fig. 16. Stress level percentage distribution based on Self-Assessment Test. Results involving subjects classified in terms of Emotional Oriented Stress Coping Strategy[4]. 


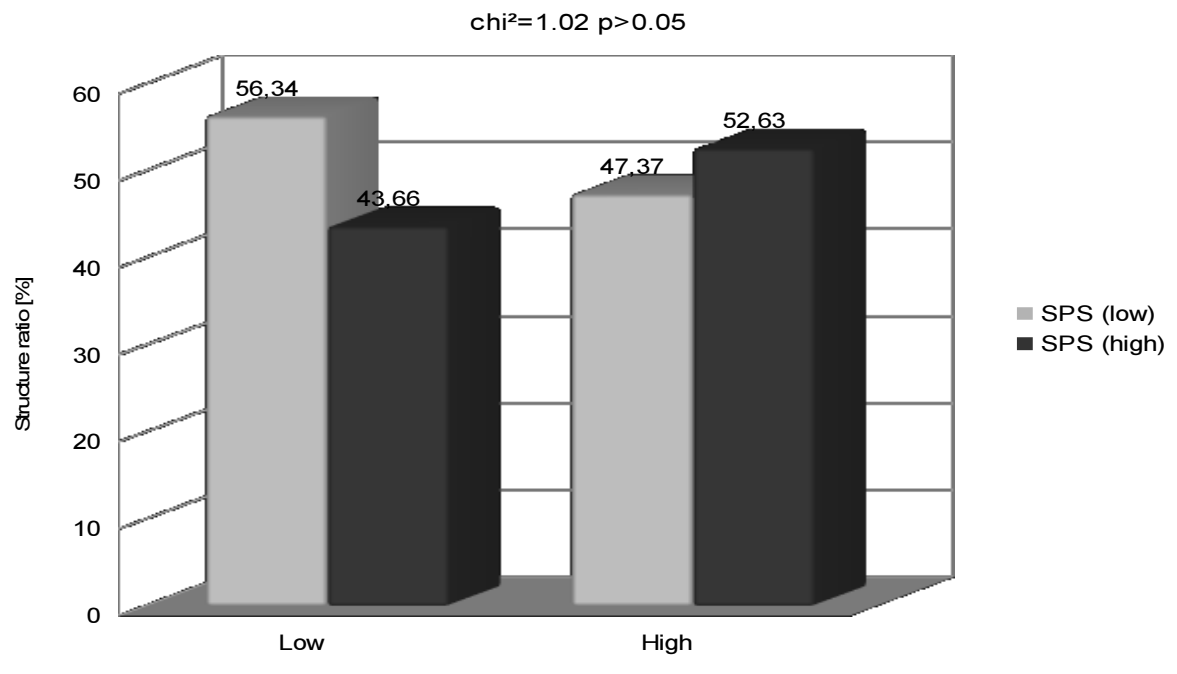

\begin{tabular}{lll}
\hline & Low & High \\
\hline SPS (low) & 56.34 & 47.37 \\
\hline SPS (high) & 43.66 & 52.63 \\
\hline
\end{tabular}

Fig. 17 Stress level percentage distribution based on Self-Assessment Test. Results involving subjects classified in terms of Avoidance Coping [4].

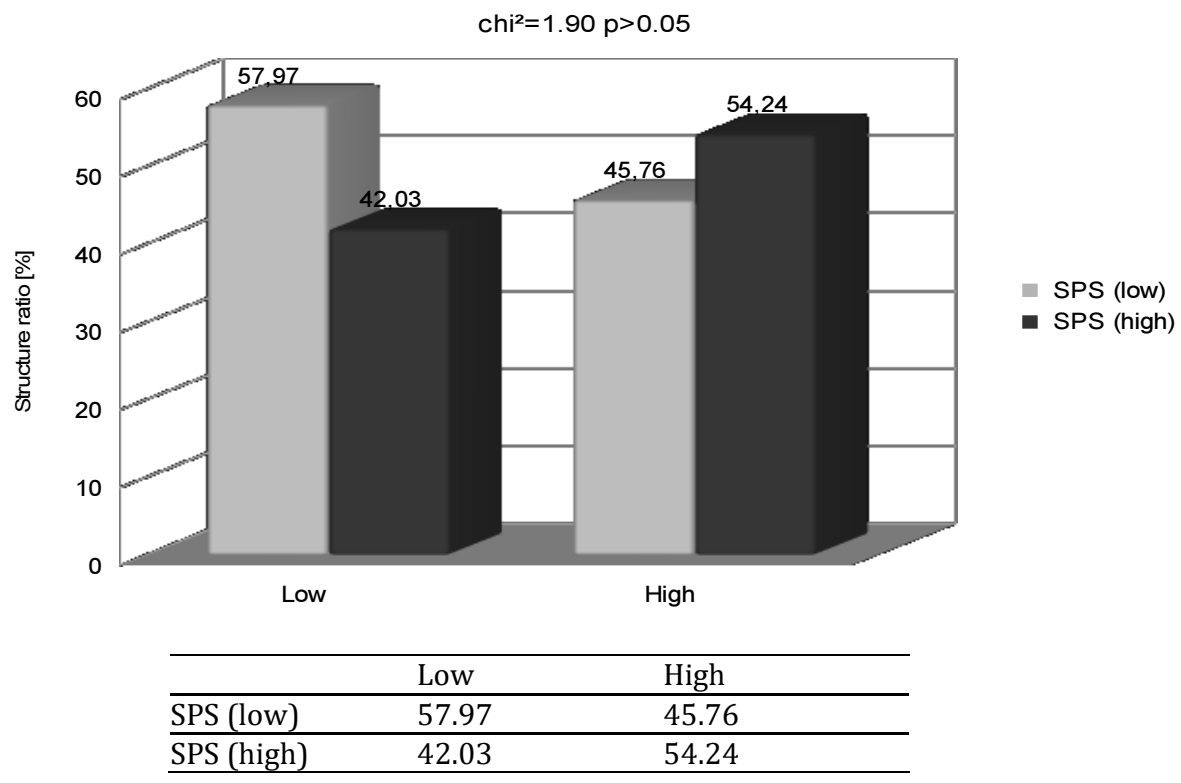

Fig. 18 Stress level percentage distribution based on Self-Assessment Test. Results involving subjects classified in terms of Distraction [4]

While discussing the strategies of coping with stress on the basis of the obtained results, attention should be paid to two of them: the strategy oriented on emotions as well as that involving engagement in supplementary activities.

A high level obtained for both strategies resulted in a significant increase in the stress experienced by the subjects. There is also an observable tendency towards the strategy related to social diversion and a high or low stress level. Graphic interpretation of the stress coping strategies is provided in fig. 15, 16, 17, 18 \& 19. 


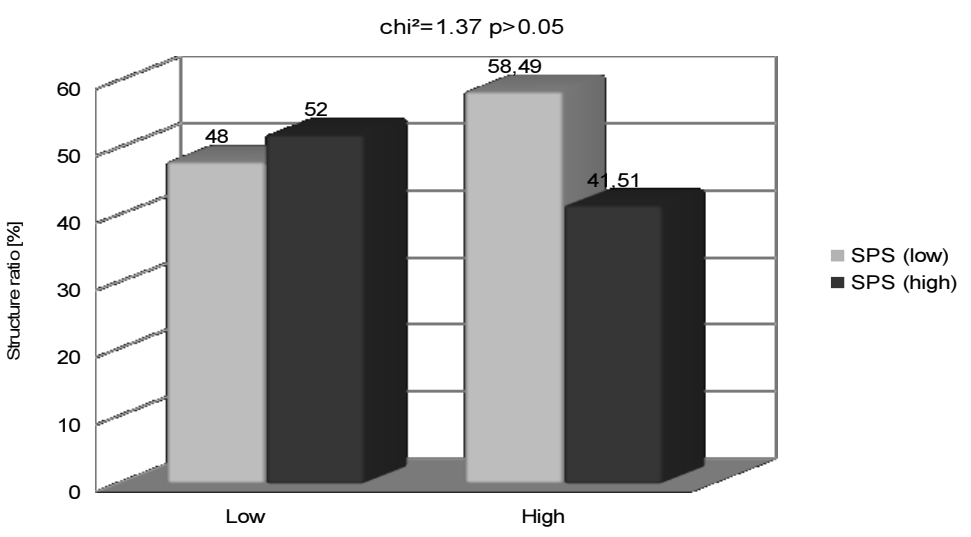

\begin{tabular}{lll}
\hline & Low & High \\
\hline SPS (low) & 48 & 58.49 \\
\hline SPS (high) & 52 & 41.51 \\
\hline
\end{tabular}

Fig. 19. Stress level percentage distribution based on Self-Assessment Test. Results involving subjects classified in terms of Social Diversion [4]

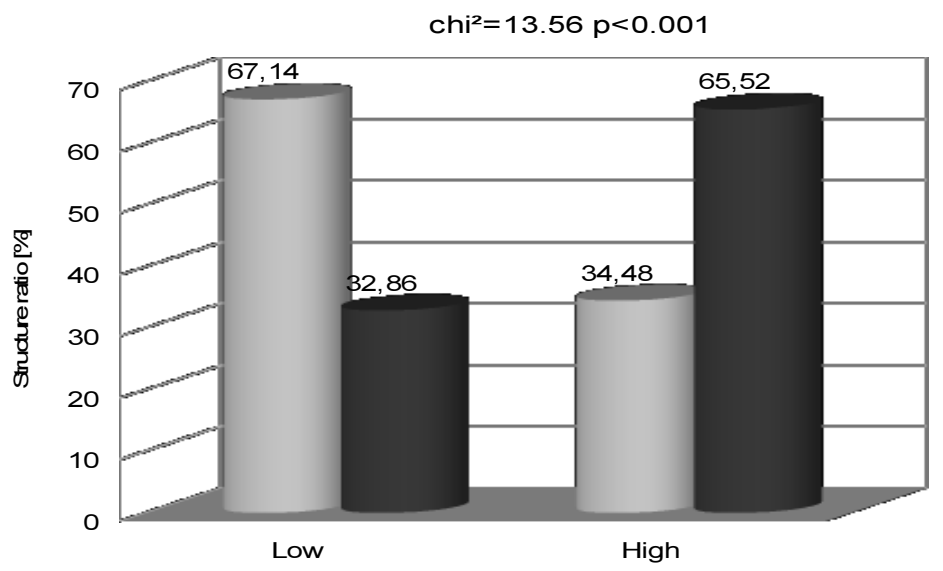

SPS (low)

- SPS (high)

\begin{tabular}{lll}
\hline & Low & High \\
\hline SPS (low) & 67.14 & 34.48 \\
\hline SPS (high) & 32.86 & 65.52 \\
\hline
\end{tabular}

Fig. 20. Stress level percentage distribution (Self-Assessment Test). Results involving subjects classified based on S-Anxiety scale of STAI test (temporary condition of "state anxiety") [4] 


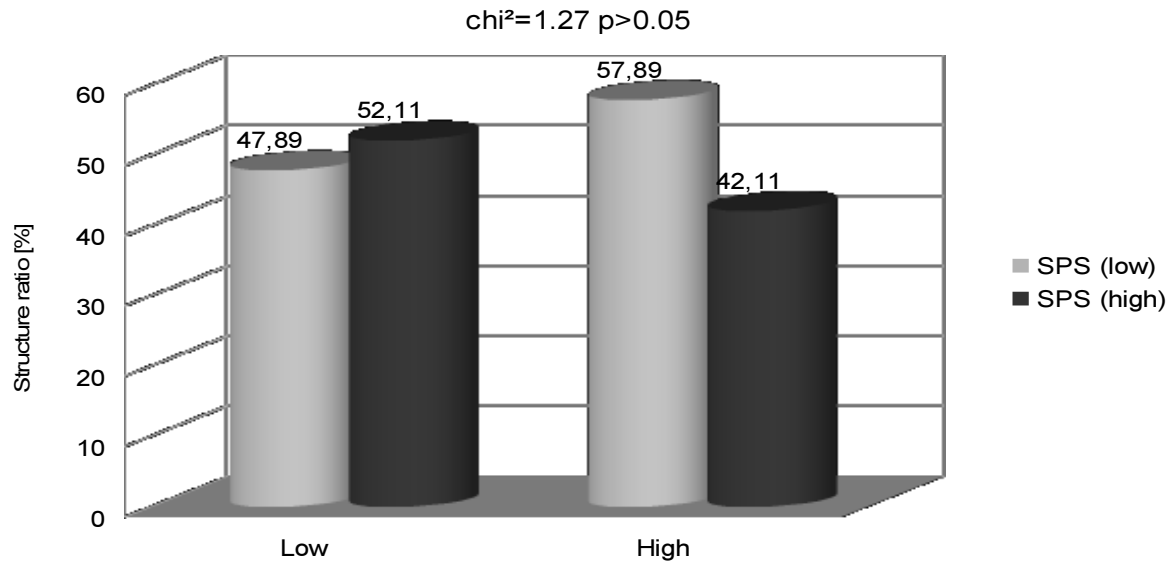

\begin{tabular}{lll}
\hline & Low & High \\
\hline SPS (low) & 47.89 & 57.89 \\
\hline SPS (high) & 52.11 & 42.11 \\
\hline
\end{tabular}

Fig. 21. Stress level percentage distribution (Self-Assessment Test). Results involving subjects classified based on T-Anxiety scale of STAI Test (long-standing quality of "trait anxiety") [4].

The presented test results confirm that subjects experiencing anxiety as a state, felt more stress than those with anxiety as a trait (fig. 20,21).
Moreover, the subjects experiencing a higher level of anxiety as a state evaluated the level of stress as higher.

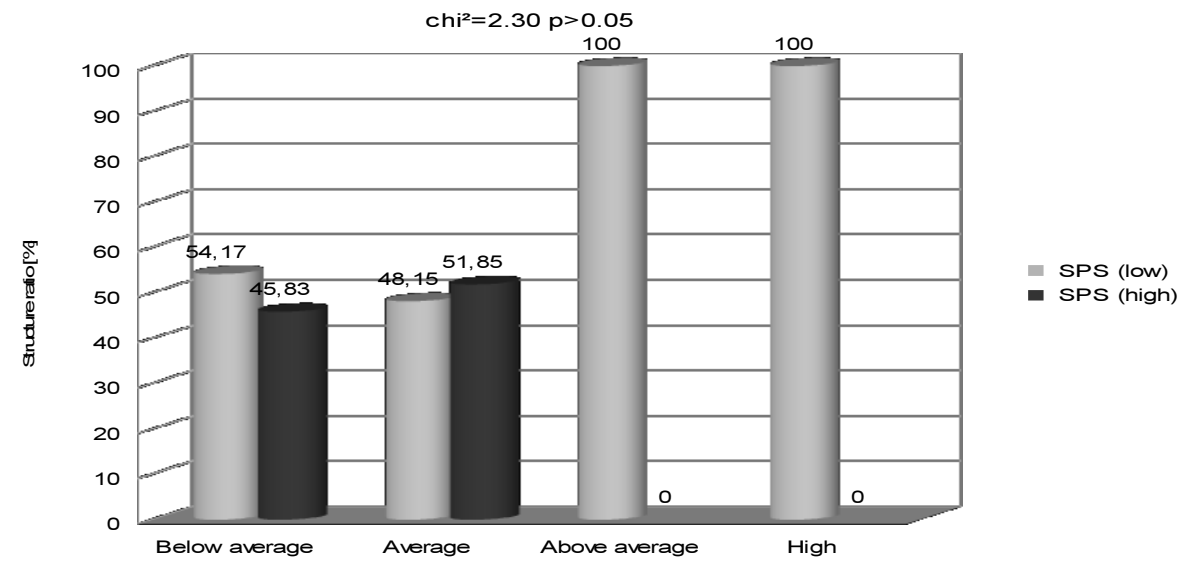

\begin{tabular}{lllll}
\hline & Below average & Average & Above average & High \\
\hline SPS (low) & 54.17 & 48.15 & 100 & 100 \\
\hline SPS (high) & 45.83 & 51.85 & 0 & 0 \\
\hline
\end{tabular}

Fig. 22. Stress level percentage distribution (Self-Assessment Test). Results involving subjects grouped based on Raven's Matrix test score [4]. 
Persons characterised by a higher level of intellectual development experienced stress at a statistically significant lower level as compared with the subjects with a lower intellectual level [4].

Subjects with a higher intellectual level were less susceptible to stress than persons with lower intellect, which had a significant impact on their process of acquiring theoretical and practical knowledge. Persons with higher intellectual capacities adapted more quickly to diving conditions, as well as obtained better results in performing practical tasks (fig. 22).

An examination into the level of positioning of the sense of control indicated an occurrence of a

statistically significant correlation with the evaluation of the stress level. The subjects with an internal positioning of the sense of control indicated a low selfassessment in relation to the stress level, whereas those with an external sense of control showed a tendency to experience a high level stress [4].

\section{DISCUSSION OF RESULTS}

On the basis of the performed tests it may concluded that the obtained results confirmed the visible stress dynamics in the subjects.

The results indicate a statistically significant difference in the levels of experienced stress in the subjects in the three phases of the study, i.e.: at the beginning, in the middle and at the end of training.

The analysis of results of the levels of experienced stress in the three parts of the course indicates that the trainees felt stress mainly during its practical parts. The contact with the aquatic environment, with which they were not familiarised on a daily basis, was a new experience, inducing a certain mental tension. The obtained results prove that the majority of subjects were highly emotional, with each encounter with a new difficult situation evoking strong emotions in them.

The stress coping strategies showed a statistically significant correlation with the stress self-assessment: subjects preferring the strategies connected with a high level of concentration on emotions or distracting attention from the existing problem were characterised by a high level assessment of the experienced stress.

The preferred strategy within the tested population was the emotion oriented method of coping with stress. The said strategy is characteristic of persons who tend to concentrate on themselves, on their own emotional state, such as anger, guilt, tension, while experiencing stress.

Moreover, they show a tendency towards wishful thinking and fantasising [6]. Also, the subjects with high levels of this strategy highly evaluated their stress levels. During the three stages of the study, the subjects showing high tendencies towards the strategy based on avoidance indicated high stress levels.

The trainees who tended to assess the experienced stress at a higher level also obtained high results in the scale related to engaging in supplementary activities and seeking social contacts.

The personality dimensions of Conscientiousness and Neuroticism indicated a relevant significance in the evaluation of the stress level experienced by subjects in the course of the performed diving tasks.
Neuroticism means susceptibility to experiencing negative emotions such as anxiety, confusion, dissatisfaction, anger, guilt and sensitivity to psychological stress. Due to the fact that negative emotions affect the individual's skills to adapt to environment, neurotic persons tend to present irrational ideas, are relatively incapable of controlling their impulses or coping with stress [7].

Since the subjects with a high neuroticism level are more susceptible to experiencing stronger stress as compared with people with a low indicator of this trait, in the process of qualifying and selecting candidates for professional divers it is necessary to consider this feature, as it may have an effect on obtaining a negative result in the diving course and dropping out.

Briskness as a temperament dimension is seen in the tendency to reacting quickly (maintaining a high activity pace and easy changes in reaction maintenance) to changes in the environment [8].

This characteristic has a significant meaning for the evaluation of the stress level: the higher its level, the lower the level of stress. Positive correlation is also noted in relation to activity - a higher level of activity effects in a higher level of experienced stress.

A high level of emotional reactivity and perseveration led to an increased susceptibility to experiencing stress in the tested persons.

The study showed that the level of briskness juxtaposed with a high and low level of stress assessment confirmed that subjects with a high briskness level tended to indicate a low level of assessed stress as compared with persons with lower briskness [4].

The examination into the positioning of the sense of control proved an occurrence of a statistically significant correlation with the evaluation of the stress level. The subjects with an internal positioning of the sense of control indicated a low self-assessment in relation to the stress level, whereas those with an external sense of control showed a tendency to experience a high level stress.

The study showed that both the subjects experiencing anxiety as a state and as a trait equally experienced a high stress level.

A high anxiety level may lead to an occurrence of paradoxical reactions in the form of a reduced reactivity to threat information. It may also have a paralysing effect in a difficult situation requiring readiness in specialised tasks. Therefore it is crucial that persons with high anxiety levels are diagnosed before training commencement.

Persons characterised by a higher level of intellectual development experienced stress at a statistically significant lower level as compared with the persons with lower intellectual levels.

The subjects with a higher intellect were able to quicker adapt to the conditions of military service and had better results in performing tasks, which had a significant impact on their process of acquisition of theoretical and practical instruction. Additionally, more intellectually capable persons were able to quicker adapt to the existing conditions.

The psychological testing techniques used in the work may serve as predicators in the process of selection of candidates for professional divers; therefore their application may prove useful in carrying out a more accurate evaluation of psychological predispositions in candidates to the training courses for the said position [4]. 


\section{BibLIOGRAPHY}

1. Heszen I, Sęk H. Health and disease in the paradigm of psychological stress. Psychologia zdrowia. Warsaw: WydawnictwaNaukowe PWN; 2007; 141-159. Polish [A health and an illness within the psychological stress paradigm].

2. Anegg U, Dietmaier G, Maier A, Tomaselli F, Gabor S, Kallus KW, Smolle-Jüttner FM, Stress-induced hormon al and mood responses in scuba divers. A field study. Life Sciences 2002; 70: 2721-2734.

3. Krzyżak J, Stres nurkowania. Medycyna nurkowa. Poznań: Wydawnictwo KOOPgraf s.c.; 2006; 473-486. Polish [The diving stress].

4. Buczyński J, Analiza psychofizjologicznych uwarunkowań dynamiki stresu u kandydatów do zawodu nurka i płetwonurka.Rozprawa na stopień doktora nauk medycznych. Uniwersytet Medyczny w Łodzi; 2003. Polish [The psychophysiological analysis of the dynamics of stress conditions of a diver and a combat diver profession candidates].

5. Strelau J, [red. nauk]: Teoria stresu psychologicznego i radzenia sobie. Psychologia. Podręcznik akademicki. Jednostka w społeczeństwie i elementy psychologii stosowanej.Gdańsk: GWP; 2005; 465-492. Polish [The psychological stress and coping theory].

6. Strelau J, Jaworowska A, Wrześniewski K, Szczepaniak P, The questionnaire related to Coping in Stress Situations CISS. Standardised manual. Warsaw: The Psychological Tests Institute of the Psychological Society; 2009.

7. Zawadzki B, Strelau J, Szczepaniak P, Śliwińska M, Costa Jr PT, McCrae RR, Personality Inventory NEO-FFI. Polish adaptation. Podręcznik. Warsaw: The Psychological Tests Institute of the Psychological Society; 2010.

8. Zawadzki B, Strelau J, Formal behaviour characterisation - temperament questionnaire (FCZ-KT). Podręcznik. Warsaw: The Psychological Tests Institute of the Psychological Society; 2010.

9. Wrześniewski K, Sosnowski T, Jaworska A, Fecenec D, Stage and Trait Anxiety Inventory STAI. Warsaw: The Psychological Tests Institute of the Psychological Society; 2011.

mgr Małgorzata Remlein

Zakład Medycyny Morskiej i Hiperbaryczne

Wojskowego Instytutu Medycznego w Gdyni

gabinet@malgorzataremlein.pl

tel. +48660140488 